\title{
PRODUKTIVITAS RESIN PINUS MERKUSII JUNGH ET DE VRIESE PADA KELAS UMUR DAN KETINGGIAN TEMPAT TUMBUH YANG BERBEDA
}

\author{
Productivity of Resin Pinus Merkusii Jungh Et De Vriese in Several Class Ages and Altitudes \\ Arip Wijayanto ${ }^{1}$, Nurmadina ${ }^{2}$ \\ ${ }^{1,2)}$ Politeknik Industri Furnitur dan Pengolahan Kayu, Jalan Wanamarta Raya No.20 Kawasan Industri \\ Kendal. \\ Email:wijayanto.arip@gmail.com,nurma.dinna@gmail.com
}

Diterima: 11 Mei 2021, Direvisi: 19 Mei 2021, Disetujui: 14 Juli 2021

DOI: 10.31849/forestra.v16i2.6765

\begin{abstract}
Pine resin production is influenced by several factors, including altitudes and the different classes of age . In addition, the productivity of pine resin is also influenced by weather and climate. The aim of study that entitled oductivity of Resin Pinus Merkusii Jungh Et De Vriese in Several Class Ages and Altitudes, was to investigate pine resin productivity in Forest Management Resort Guyangan, Perum Perhutani, based on variation of altitudes and class ages classified by Perum Perhutani. This study used resin production data that taped by quare methode from Forest Management Resort Guyangan, and then data were analysed with microsoft office excel. The result of this study showed that the highest pine resin productivity is 0.22 $\mathrm{kg} /$ tree/month for class age (KU) V and IV, and the lowest pine resin productivity, i.e. $0,19 \mathrm{~kg} / \mathrm{tree} / \mathrm{month}$ is for KU VII. Based on altitudes, resin productivities for 500-799 (mdpl) and 800-999 (mdpl) were 0,22 $\mathrm{kg} /$ tree/month and 0,20 kg/tree/month respectively. Based on this study, it can be concluded that the higher altitudes the lower pine resin productivity. Meanwile basedon the age class, the productivity of pine resin in different age class shows different values.
\end{abstract}

Keywords: class age, altitude, pine resin, productivity

\begin{abstract}
ABSTRAK
Produksi resin pinus dipengaruhi oleh beberapa faktor diantaranya adalah ketinggian tempat tumbuh dan kelas umur yang berbeda. Selain itu produktivitas resin pinus juga dipengaruhi oleh cuaca dan iklim. Penelitian yang berjudul Produktivitas Resin Pinus Merkusii Jungh Et De Vriese pada Kelas Umur dan Ketinggian Tempat Tumbuh yang Berbeda ini bertujuan untuk mengetahui produktivitas resin pinus di Resort Pemangkuan Hutan (RPH) Guyangan, Perum Perhutani berdasarkan pengelompokan ketinggian tempat tumbuh dan kelas umur yang dilakukan oleh Perum Perhutani. Penelitian ini menggunakan data produksi resin Pinus yang disadap menggunakan sistem koakan pada RPH Guyangan, kemudian diolah
\end{abstract}


dan dianalisis dengan menggunakan Microsoft office excel. Hasil penelitian menunjukkan bahwa berdasarkan kelas umurnya, nilai produktivitas tertinggi dihasilkan oleh kelompok tegakan Pinus KU V dan IV yaitu sebesar $0,22 \mathrm{~kg} / \mathrm{phn} / \mathrm{bulan}$, sedangkan produktivitas terendah yaitu sebesar $0,19 \mathrm{~kg} / \mathrm{phn} / \mathrm{bulan}$ dihasilkan oleh kelompok tegakan Pinus KU VII. Hasil penelitian produktivitas resin Pinus berdasarkan ketinggian lokasi tempat tumbuh dapat diketahui bahwa besarnya produktivitas masing-masing ketinggian tempat tumbuh adalah $0,22 \mathrm{~kg} / \mathrm{phn} / \mathrm{bulan}$ untuk ketinggian 500-799 (mdpl) dan 0,20 kg/pohon/bulan untuk ketinggian 800-999 (mdpl). Berdasarkan hasil penelitian ini maka dapat disimpulkan bahwa semakin tinggi tempat tumbuh maka akan semakin menurun tingkat produktivitas resin yang dihasilkan. Sedangkan berdasarkan kelas umurnya maka produktivitas resin pinus pada kelas umur yang berbeda menunjukkan nilai yang berbeda pula.

Kata kunci: kelas umur, ketinggian tempat tumbuh, produktivitas, resin pinus

\section{PENDAHULUAN}

Salah satu hasil hutan bukan kayu yang dihasilkan dari bidang kehutanan di Indonesia adalah resin pinus. Resin pinus yang dihaslikan dari jenis pohon pinus (Pinus merkusii). Pohon Pinus merupakan salah satu spesies dari Pinus sp. yang banyak tumbuh di Indonesia, terutama Sumatera dan Jawa. Di Pulau Jawa, pohon Pinus banyak ditanam oleh Perum Perhutani, termasuk di wilayah Resot Pemangkuan Hutan (RPH) Guyangan yang berlokasi di Ponorogo. Kayu yang dihasilkan oleh pohon Pinus dapat dimanfaatkan sebagai bahan baku furnitur, kayu konstruksi, pulp, dan kertas. Kayu pinus juga terbukti mengandung senyawa yang berpotensi sebagai antioksidan dan antijamur (Wijayanto et al., 2015). Sementara itu resin yang dihasilkan oleh pohon Pinus dapat dimanfaatkan sebagai bahan baku gondorukem dan terpentin yang memiliki nilai ekonomis tinggi.

Proses pemungutan resin Pinus yang dilakukan oleh Perhutani dilakukan dengan metode koakan dan diperbaharui setiap tiga hari sekali. Oleh karena itu produktivitas dari resin yang dihasilkan sangat dipengaruhi oleh perilaku penyadap dalam memperbaharui sadapan (Wijayanto et al., 2019). Selain perilaku penyadap, Produktivitas resin pinus juga dipengaruhi oleh berbagai faktor, diantaranya adalah perbedaan umur (Evayanti et al., 2019; Sudrajat et al., 2002; Sukarno et al., 2012), perbedaan diameter (Hadiyane et al., 2015; Mampi et al., 2018; K. C.S. Rodrigues et al., 2008), luas bidang penyadapan (Darmastuti et al., 2016; Lempang, 2017), metode penyadapan 
(Hadiyane et al., 2015; Lempang, 2017) dan faktor lainnya, seperti cuaca (Kelly C.S. Rodrigues \& Fett-Neto, 2009; Wijayanto et al., 2019) dan jenis hutan (Prasetya et al., 2017). Pengaruh waktu dan cuaca telah dilaporkan oleh Wijayanto et al., (2019) yaitu pada musim kemarau produktivitas resin pinus lebih tinggi dibandingkan musim penghujan dan pada tahun 2017 terjadi peningkatan produktivitas resin pinus dari tahun sebelumnya. Hal ini diduga karena adanya musim panas sepanjang tahun. Dilaporkan oleh Kompas (2018) bahwa tercata dalam sejarah dunia bahwa tahun 2017 merupakan tahuan terpanas tanpa el nino.

Berdasarkan umurnya, pernah dilakukan penelitian produksi resin pinus dengan metode bor pada tegakan pinus KU III s.d. KU VI di Malang (Sukarno et al., 2012). Penelitian sebelumnya juga telah melaporkan produksi pinus dengan metode koakan pada tegakan KU VII di Jember (Evayanti et al., 2019). Sementara itu dalam penelitian lainnya juga telah dilaporkan produksi resin Pinus berdasarkan umur yang di bagi dalam tiga kelompok yaitu 15 tahun,
18 tahun, dan 24 tahun (Sudrajat et al., 2002). Pembagian kelompok umur tersebut tidak sesuai dengan pembagian KU yang dilakukan oleh Perum Perhutani, yaitu pengelompokkan KU pada setiap rentang 5 tahun. Sampai saat ini belum pernah dilakukan penelitian secara komprehensif terkait produktivitas resin Pinus pada kelompok KU yaitu dari KU III s.d. KU VII dengan kategori ketinggian tempat tumbuh yang berbeda.. Oleh karena itu, penelitian ini bertujuan untuk mengetahui tingkat produktivitas resin Pinus pada ketinggian tempat tumbuh 500-799 (mdpl) dan 800-999 (mdpl), dimana pada dua ketinggian tersebut banyak ditanam pohon pinus sesuai klasifikasi ketinggian tempat tumbuh yang dilakukan oleh Perum Perhutani. Penelitian ini juga bertujuan mengetahui produktivitas resin pada berbagai KU, yaitu KU I s.d. KU VII pada tegakan Pinus di RPH Guyangan, Perum Perhutani.

\section{METODE PENELITIAN}

Penelitian ini menggunakan data yang dihimpun dari laporan produksi resin pinus di Perum Perhutani, RPH Guyangan, BKPH Ponorogo Barat, KPH Lawu Ds. pada Bulan 
Januari s.d. Agustus tahun 2017. Data yang digunakan adalah data produksi resin pinus pada ketinggian 500-799 (mdpl) dan 800-999 (mdpl), dan KU I s.d. KU VII, yang luas totalnya adalah 283,9 Ha dari toal luas sadapan pinus RPH Guyangan sebesar 464, 6 Ha. Luas sadapan yang dimiliki oleh RPH Guyangan adalah sebesra 80\% dari total luasan sadapan BKPH Ponorogo Barat (593,0 Ha).

Data tahun 2017 digunakan karena berdasarkan hasil penelitian Wijayanto et al., (2019) produktivitas resin pinus pada musim kemarau lebih tinggi dibandingkan musim penghujan, dan pada tahun 2017 terjadi peningkatan produktivitas resin pinus dari tahun sebelumnya, yang diduga disebabkan oleh adanya musim panas sepanjang tahun. Dilaporkan oleh Kompas (2018) bahwa tercata dalam sejarah dunia bahwa tahun 2017 merupakan tahuan terpanas tanpa el nino. Oleh karena produksi resin pinus dipengaruhi oleh cuaca, maka adanya musim panas yang lebih lama jelas mempengaruhi produksi resin pinus. Penelitian ini diharapkan dapat memberikan informasi tentang produktivitas resin pinus di saat musim kemarau yang panjang mengingat adanya fenomena el nino yang mungkin terjadi setiap 2 s.d. 8 tahun sekali.

Tegakan pinus pada RPH Guyangan berasal dari kegiatan penanaman rutin oleh Perum Perhutani dengan jenis Pinus merkusii. Pemungutan resin pinus yang dilakukan oleh Perum Perhutani menggunakan metode koakan/ quare. Untuk merangsang produksi resin maka disemprotkan stimulansia setelah pembaharuan koakan. Pembaruan koakan sendiri umunya dilakukan setiap tiga hari sekali. Data yang didapatkan dari RPH Guyangan diantaranya adalah data potensi sadapan (jumlah pohon, ketinggian tempat tumbuh, kelas umur dan luas sadapan) dan data produksi bulanan resin pinus. Kemudian data yang diperoleh direkapitulasi dalam bentuk tabel dan diolah menggunakan Microsoft office excel.

Produktivitas resin pinus diperoleh dengan membandingkan data produksi resin terhadap jumlah pohonnya. Produktivitas resin tersebut dianalisis berdasarkan ketinggian lokasi tempat tumbuh dan kelas umur (KU) dari tegakan pinus. Ketinggian 
lokasi tempat tumbuh diklasifikasikan menjadi dua, yaitu ketinggian 500-799 (mdpl) dan 800-999 (mdpl). Sedangkan pengklasifikasian kelas umur mengikuti peraturan yang ditentukan oleh Perhutani, yaitu KU III merupakan tegakan berumur 10 tahun s.d. 15 tahun, KU IV tegakan berumur 16 tahun s.d. 20 tahun, dan seterusnya berjarak 5 tahun sampai dengan KU VII untuk tegakan berumur 30 tahun s.d. 35 tahun.

\section{HASIL DAN PEMBAHASAN}

Tabel 1 menampilkan data potensi sadapan resin pinus pada RPH Guyangan.
Berdasarkan ketinggiannya, potensi sadapan yang dimiliki oleh RPH Guyangan secara umum terletak pada ketinggian 500-799 (mdpl) dan 800-999 (mdpl) yaitu dengan luas sadapan untuk masing-masing kelompok ketinggian adalah 161,3 Ha dan 122,6 Ha. Berdasarkan jumlah pohonnya untuk masingmasing ketinggian tersebut memiliki pohon sebanyak 133.460 pohon dan 73.043 pohon. Berdasarkan kelas umurnya, potensi sadapan tertinggi dimiliki oleh kelompok $\mathrm{KU} \mathrm{V}$ dengan luas sadapan 138,26 Ha dengan jumlah pohon sebanyak 125.089 phn.

Tabel 1. Potensi Sadapan RPH Guyangan

\begin{tabular}{|c|c|c|c|c|c|c|}
\hline \multirow{3}{*}{$\begin{array}{l}\text { Kelas } \\
\text { Umur }\end{array}$} & \multicolumn{4}{|c|}{ Ketinggian (mdpl) } & \multirow{2}{*}{\multicolumn{2}{|c|}{ Total }} \\
\hline & \multicolumn{2}{|c|}{$500-799$} & \multicolumn{2}{|c|}{$800-999$} & & \\
\hline & Luas (Ha) & Jumlah Pohon & Luas (Ha) & Jumlah Pohon & Luas (Ha) & Jumlah Pohon \\
\hline III & 14,7 & $11.216,0$ & 17,3 & $7.699,0$ & 32,0 & $18.915,0$ \\
\hline IV & 10,4 & $8.237,0$ & 35,7 & $16.521,0$ & 46,1 & $24.758,0$ \\
\hline V & 110,2 & $101.813,0$ & 28,0 & $23.276,0$ & 138,2 & $125.089,0$ \\
\hline VI & 24,1 & $11.785,0$ & 39,6 & $25.047,0$ & 63,7 & $36.832,0$ \\
\hline VII & 1,9 & 409,0 & 2,0 & 500,0 & 3,9 & 909,0 \\
\hline Total & 161,3 & $133.460,0$ & 122,6 & 73.043 .0 & 283,9 & $206.503,0$ \\
\hline
\end{tabular}

Rekapitulasi produksi resin pinus di RPH Guyangan ditampilkan pada Tabel 2. Total produksi resin Pinus di RPH tersebut adalah sebesar $356.796 \mathrm{~kg}$. Produksi resin tertinggi berdasarkan ketinggian tempat tumbuhnya dihasilkan oleh kelompok 
tegakan Pinus pada ketinggian 500-799 (mdpl) diikuti ketinggian 800-999 (mdpl), yaitu besarnya adalah $234.787 \mathrm{~kg}$ dan $122.009 \mathrm{~kg}$. Pengaruh perbedaan ketinggian tempat tumbuh terhadap produktivitas resin pinus menunjukkan semakin tinggi lokasi tempat tumbuh maka terdapat kecenderungan semakin rendah produktivitasnya. Sedangkan berdasarkan kelas umurnya, dapat diketahi bahwa produksi resin pinus paling tinggi sebesar $224.543 \mathrm{~kg}$ dihasilkan dari kelompok tegakan KU V diikuti oleh KU IV (58.229 $\mathrm{Kg})$.

Tingginya resin yang dihasilkan berkorelasi positif dengan jumlah pohon sadapan (Tabel 1 dan Tabel 2), yaitu secara umum semakin banyak jumlah pohon sadapan maka semakin banyak pula resin yang dihasilkan. Sejalan dengan penelitiannya sebelumnya, bahwa jumlah pohon berkorelasi positif dengan tingkat produksi resin pinus yang dihasilkan (Wijayanto et al., 2019).

Rata-rata produktivitas resin pinus per pohon pada setiap bulannya disajikan pada Gambar 1. Terjadi fluktuasi produktivitas pada setiap bulannya, yaitu terjadi penurunan dari bulan Januari s.d. Maret dan terjadi peningkatan dari bulan April s.d. Juni. Kemudian kembali menurun pada Juli dan meningkat pada bulan Agustus. Produktivitas resin tertinggi terjadi pada bulan Juni yaitu sebesar 0,31 kg/phn/bulan, sedangkan produktivitas terendah terjadi pada bulan Maret yaitu sebesar $0,15 \mathrm{~kg} / \mathrm{phn} / \mathrm{bulan}$. Fenomena ini disebabkan oleh adanya variasi musim yang berpengaruh terhadap produksi resin, yaitu pada musim panas (bulan Mei s.d. Agustus) produktivitas cenderung lebih tinggi dibandingkan dengan produktivitas pada musim penghujan (bulan Januari s.d. April).

Tabel 2. Produksi Resin Pinus RPH Guyangan

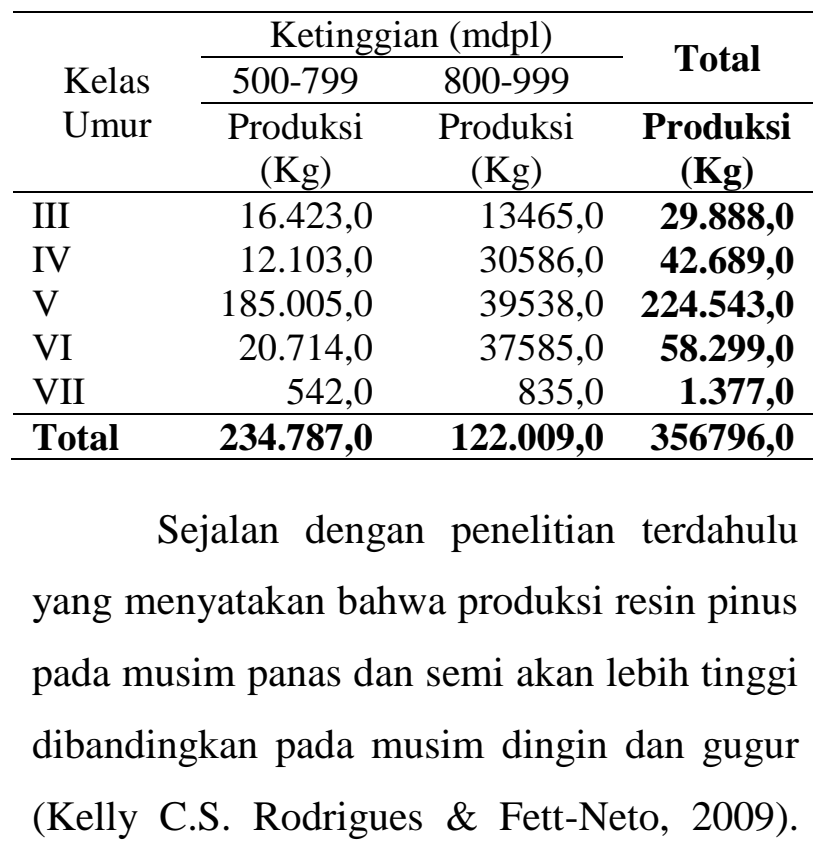


Penelitian lainnya juga menyatakan bahwa pada saat musim panas umumnya produksi resin akan cenderung lebih tinggi dibandingkan saat musim penghujan dengan suhu yang rendah (Wijayanto et al., 2019). Cuaca yang dingin dapat memperlambat aliran getah sehingga produksinya menurun. Selain pengaruh cuaca, tingkat produktivitas resin pinus juga dipengaruhi oleh perilaku penyadap dalam pembaruan bidang sadapan. Rendahnya produktivitas pada bulan Januari s.d. April diduga karena pada saat musim penghujan para penyedap lebih memilih untuk kegiatan bercocok tanam dibandingkan melakukan penyadapan, sehingga pembaharuan sadapan menjadi tidak rutin.

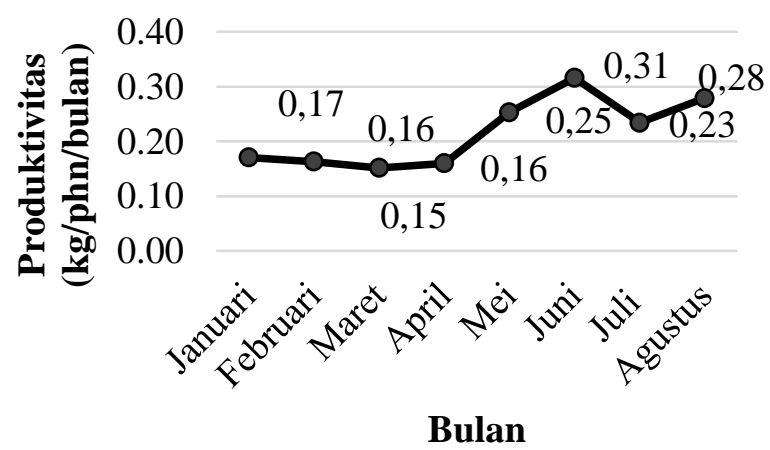

Gambar 1. Produktivitas Resin Pinus Berdasarkan Bulan
Perbandingan produktivitas resin pinus pada KU yang berbeda disajikan pada Gambar 2. Secara umum terjadi fluktuasi tingkat produktivitas pada KU yang berbeda. Produktivitas Resin meningkat dari KU III s.d. KU V kemudian menurun pada KU VI dan KU VII. Produktivitas tertinggi, yaitu sebesar 0,22 kg/phn/bulan dihasilkan oleh kelompok tegakan KU IV dan V, sedangkan produktivitas terendah dihasilkan oleh kelompok tegakan KU VII yaitu sebesar 0,19 $\mathrm{kg} / \mathrm{phn} / \mathrm{bulan}$.

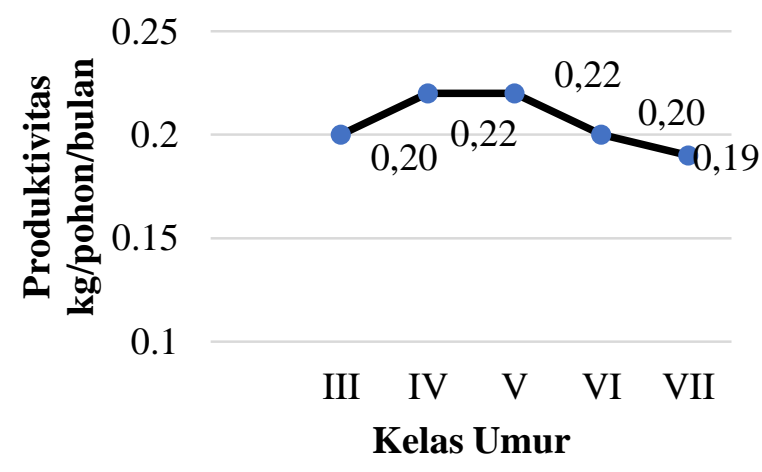

Gambar 2. Produktivitas Resin Pinus Berdasarkan Kelas Umur

Hasil Penelitian ini mendukung hasil penelitian sebelumnya yang menunjukkan bahwa produksi resin pinus diantara kelas umur yang berbeda menunjukkan nilai yang berbeda pula. Produksi resin pinus mengalami peningkatan dari KU III (36,5 g/2 
lubang/1 hari) ke KU IV (62,9 g/2 lubang/1 hari) dan mengalami penurunan pada $\mathrm{KU} \mathrm{V}$ (24,61 g/2 lubang/1 hari), kemudian mengalami kenaikan pada KU VI (38,3 g/2 lubang/1 hari) (Sukarno et al., 2012). Sementara itu penelitian terdahulu lainnya melaporkan bahwa penyadapan pada tegakan pinus umur 15 tahun, 18 tahun, dan 24 tahun menujukkan semakin tinggi umur maka semakin rendah tingkat produksinya (Sudrajat et al., 2002). Dilaporkan pada penelitian sebelumnya bahwa produksi resin Pinus KU VII, nilai produktivitas rata-ratanya adalah 8,42 g/koakan/hari (Evayanti et al., 2019).

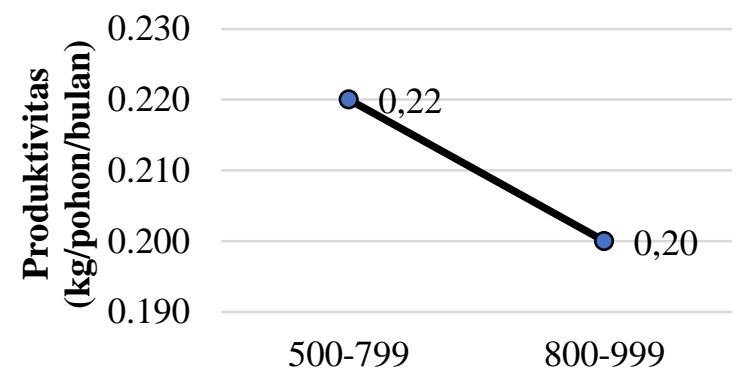

Ketinggian Tempat Tumbuh (mdp

Gambar 3. Produktivitas Resin Pinus Berdasarkan Ketinggian Tempat Tumbuh

Pengaruh perbedaan ketinggian tempat tumbuh terhadap produktivitas resin pinus menunjukkan semakin tinggi lokasi tempat tumbuh maka produktivitasnya semakin rendah (Gambar 3). Nilai produktivitas tertinggi dihasilkan oleh tegakan pinus pada ketinggian 500-799 (mdpl) yaitu sebesar 0,22 kg/phn/bulan, kemudian diikuti oleh tegakan pinus pada ketinggian 800-999 (mdpl), nilai produktivitasnya $\quad 0,20 \quad \mathrm{~kg} / \mathrm{phn} / \mathrm{bulan}$. Pengaruh ketinggian tempat tumbuh terhadap produksi resin diduga semakin tinggi tempat tumbuh maka akan semakin rendah suhu udara dan intensitas cahayanya. Rendahnya suhu dan intensitas cahaya menyebabkan resin pinus akan cepat menggumpal. Gumpalan-gumpalan tersebut akan menghambat aliran resin yang dihasilkan. Selain kelas umur dan ketinggian lokasi tempat tumbuh, perbedaan produktivitas resin pinus dapat disebabkan oleh berbagai faktor diantaranya perbedaan diameter (Hadiyane et al., 2015; Mampi et al., 2018; K. C.S. Rodrigues et al., 2008), luas bidang penyadapan (Darmastuti et al., 2016; Lempang, 2017), metode penyadapan (Hadiyane et al., 2015; Lempang, 2017) cuaca (Kelly C.S. Rodrigues \& Fett-Neto, 
2009; Wijayanto et al., 2019), dan perilaku penyadapan (Wijayanto et al., 2019).

\section{KESIMPULAN}

Ketinggian tempat tumbuh dan kelas umur tegakan pinus memberikan pengaruh terhadap adanya perbedaan produktivitas resin pinus yang dihasilkan. Berdasarkan kelas umurnya, produktivitas tertinggi yaitu sebesar 0,22 kg/phn/bulan dihasilkan oleh kelompok tegakan KU IV dan V, sedangkan produktivitas terendah dihasilkan oleh kelompok tegakan KU VII yaitu sebesar 0,19 kg/phn/bulan. Sedangkan berdasarkan ketinggian tempat tumbuh secara umum dapat dikatakan bahwa semakin tinggi tempat tumbuh maka akan semakin menurun tingkat produktivitas resin yang dihasilkan. Nilai produktivitas tertinggi dihasilkan oleh tegakan pinus pada ketinggian 500-799 (mdpl) yaitu sebesar $0,22 \mathrm{~kg} / \mathrm{phn} / \mathrm{bulan}$ diikuti nilai produktivitas tegakan pinus pada ketinggian 800-999 (mdpl), yaitu sebesar $0,20 \mathrm{~kg} / \mathrm{phn} / \mathrm{bulan}$.

\section{UCAPAN TERIMA KASIH}

Penulis mengucapkan terima kasih kepada Perum Perhutani, RPH Guyangan, BKPH Ponorogo Barat, KPH Lawu Ds. yang telah membantu penulis dalam memperoleh data potensi sadapan dan produksi resin pinus sehingga penelitian ini dapat terlaksana dengan lancar dan baik.

\section{DAFTAR PUSTAKA}

Darmastuti, I. N., Santosa, G., \& Matangaran, J. R. (2016). Penyempurnaan teknik penyadapan resin pinus dengan metode kuakan (Improvement of Pine Resin Tapping with Quare Method). Jurnal Penelitian Hasil Hutan, 34(1), 23-32.

Evayanti, D., Wulandari, F. T., \& Rini, D. S. (2019). Produktivitas Dan Kualitas Getah Pinus Pehutani Kelas Umur Vii Di Kesatuan Pengelolaan Hutan Jember. Jurnal Belantara, 2(2), 127. https://doi.org/10.29303/jbl.v2i2.84

Hadiyane, A., Sulistyawati, E., Asharina, W. P., \& Dungani, R. (2015). A study on production of resin from pinus merkusii jungh. Et De vriese in the Bosscha observatory area, west Java-Indonesia. Asian Journal of Plant Sciences, 14(2), 
89-93.

https://doi.org/10.3923/ajps.2015.89.93

Kompas. (2018). Sah , 2017 adalah Tahun

Terpanas Tanpa El Nino. Kompas.

https://www.kompas.com/sains/read/202

1/01/05/173200923/bisa-picu-indonesia-

alami-tahun-basah-2021-ini-manfaat-

baik-la-nina?page $=$ all

Lempang, M. (2017). Studi Penyadapan

Getah Pinus Cara Bor Dengan Stimulan

H2So4. Jurnal Penelitian Hasil Hutan, 35(3),221-230.

https://doi.org/10.20886/jphh.2017.35.3

221-230

Mampi, B., Hapid, A., Kehutanan, J.,

Kehutanan, F., Tadulako Jl Soekarno-

Hatta Km, U., \& Sulawesi Tengah, P.

(2018). Produksi Getah Pinus (Pinus

Merkusii Jung Et De Vriese) Pada

Berbagai Diameter Batang

Menggunakan Sistem Koakan Di Desa

Namo Kecamatan Kulawi Kabupaten

Sigi. Jurnal Warta R, 6(N : 2579-6287), 42-48.

Prasetya, C. Della, Syaufina, L., \& Santosa, G. (2017). The effect of various types of forest fires on pine resin productivity in
Gunung Walat University Forest, Sukabumi, Indonesia. Biodiversitas, $18(1)$, 476-482. https://doi.org/10.13057/biodiv/d180105 Rodrigues, K. C.S., Azevedo, P. C. N., Sobreiro, L. E., Pelissari, P., \& FettNeto, A. G. (2008). Oleoresin yield of Pinus elliottii plantations in a subtropical climate: Effect of tree diameter, wound shape and concentration of active adjuvants in resin stimulating paste. Industrial Crops and Products, 27(3), $322-327$.

https://doi.org/10.1016/j.indcrop.2007.1

1.010

Rodrigues, Kelly C.S., \& Fett-Neto, A. G. (2009). Oleoresin yield of Pinus elliottii in a subtropical climate: Seasonal variation and effect of auxin and salicylic acid-based stimulant paste. Industrial Crops and Products, 30(2), 316-320.

https://doi.org/10.1016/j.indcrop.2009.0 6.004

Sudrajat, R., Setyawan, D., \& Sumadiwangsa, S. (2002). Pengaruh Diameter Pohon, Umur dan Kadar 
Stimulan terhadap Produktivitas Getah

Tusam. Buletin Penelitian Hasil Hutan, 20(2), 143-158.

Sukarno, A., Hardiyanto, E. B., Marsoem, S.

N., \& Na, M. (2012). Pengaruh

Perbedaan Kelas Umur terhadap

Produktivitas Getah Pinus merkusii

Jungh et de Vriese Ras Lahan Jawa

melalui Penyadapan Getah Metode Bor

Effect Of Among Age Class Differences

On Oleoresin Production Pinus merkusii

Jungh Et De Vriese Java Land Race.

Pal, 3(1), 28-31.

Wijayanto, A., Dumarçay, S., Gérardin-

Charbonnier, C., Sari, R. K., Syafii, W.,

\& Gérardin, P. (2015). Phenolic and lipophilic extractives in Pinus merkusii Jungh. et de Vries knots and stemwood. Industrial Crops and Products, 69, 466471.https://doi.org/10.1016/j.indcrop.20

15.02 .061

Wijayanto, A., Wardhana, T. W., Nurmadina,

\& Darwitono. (2019). Produktivitas dan

Perbandingan Produksi Resin Pinus

Merkusii Jungh Et De Vriese terhadap

Net Progress Schedule ( NPS ) yang

Ditetapkan Perhutani. Silva Tropika,
$3(2)$

199-205.

https://online-

journal.unja.ac.id/STP/article/view/8151

/5059 